Naunyn-Schmiedebergs Arch. exp. Path. u. Pharmak. 251, $39-47$ (1965)

From the Pharmacology Research Laboratories, The Upjohn Company Kalamazoo, Michigan

\title{
Cardiovascular Actions of the Hypotensive Agent, N, N-Diallylmelamine (U-7720)*
}

By

\author{
Walter A. Freyburger, James R. Weeks, and Donalo W. Ducharme ** \\ With 3 Figures in the Text \\ (Received January 8, 1965)
}

A technique commonly employed for preliminary evaluation of cardiovascular and autonomic effects of chemical substances depends upon the use of anesthetized dogs. The compound to be studied is administered intravenously before and after agents of known autonomic activity and effects upon arterial pressure are observed.

Diallylmelamine [2,4-diamino-6-(diallylamino)-s-triazine, U-7720] was tested by this technique on two occasions in preparation for its study in man as a gastric antisecretory agent. In both tests it was inactive. However, when this compound was administered to trained, unanesthetized dogs, it was surprisingly found to have pronounced and prolonged hypotensive activity.<smiles>C=CCN(CC=C)c1nc(N)nc(N)n1</smiles>

The present report describes some cardiovascular effects of this interesting agent when administered acutely and chronically to trained, unanesthetized animals.

\section{Methods \\ 1. Blood pressure}

Dogs were trained to lie quietly on their backs, the femoral artery punctured using a 24 gauge needle, and pressure recorded through a Statham P23g transducer on a Grass Model 5 polygraph. Mean arterial pressure was obtained by electronic damping. All measurements were made in a sound attenuated room which provided

* Presented in part at the 1962 fall meeting of the American Society for Pharmacology and Experimental Therapeutics in Nashville, Tennessee (Freyburger et al. 1962).

** Present address: Department of Pharmacology, Medical School, University of Michigan, Ann Arbor, Michigan. 
both isolation and relative freedom from extraneous sounds. Mean blood pressure in rats was measured directly from indwelling aortic cannulas by the method of WEEKS and JoNES (1960).

Renal hypertension in dogs was induced by the method of GoldbLatT et al. (1934) and in rats by the method of Grollman (1944).

\section{Cardiac Output}

The direct Fick method was used on trained unanesthetized dogs in which arterial and venous cannulas (size PE 50 polyethylene tubing) had previously been implanted. Venous blood was obtained from the right ventricle, the cannula being passed down the external jugular vein and its position monitored by pressure pulse tracings on the polygraph. Arterial blood was obtained from a cannula passed down a common carotid into the thoracic aorta. Both catheters were brought subcutaeously to exit through the skin between the shoulder blades. Tubing was anchored in the tissues using flared segments of size PE 100 tubing (HeAtLEY and WeEKs 1964). Blood pressure in these dogs was measured through the aortic cannula. Oxygen content was determined using a Natelson micro-gasometer. Blood samples were drawn in oiled syringes and stored in ice (not over 2 hours) in plastic capped $4 \mathrm{ml}$ vials containing about a $5 \mathrm{~mm}$ layer of mercury and filled completely with mineral oil. Small holes in the cap permitted adding of blood samples and displacement of the mineral oil. Oxygen consumption was measured for at least five minutes using a Benedict-Roth metabolimeter and a commercial rubber face-mask for dog use with an anaesthesia machine. Blood samples were drawn during the period oxygen consumption was being measured.

\section{Sympathetic reactivity}

The blood pressure rise following bilateral clamping of the common carotid arteries for one minute was used as a measure of sympathetic reactivity. Trained normotensive dogs with carotid arteries exteriorized in skin tubes according to the technique of VAN LEERSUM (1911) were used. Blood pressure was recorded continuously by direct femoral artery puncture.

\section{Results}

\section{Blood pressure and heart rate in normotensive dogs}

Large single oral doses (25 and $50 \mathrm{mg} / \mathrm{kg}$ ) of diallylmelamine were given to four unanesthetized normotensive dogs (Table 1). After a latent period of up to two hours there was a marked tachycardia which persisted for four days, and a disappearance of the normal sinus arrhythmia. Since this is the typical response to vagal blockade in the unanesthetized dog, the possibility that diallylmelamine was an anticholinergic agent was tested by administering small intravenous doses of methacholine chloride $(2.5$ and $10 \mu \mathrm{g})$ to pretreated dogs. While the expected brief hypotensive response to methacholine was minimal four to six hours after diallylmelamine, it was essentially normal by the following morning. Thus, the prolonged tachycardia seen in dogs does not reflect classical anticholinergic activity.

The hypotensive response to diallylmelamine followed the cardioaccelerator effect. It was gradual in onset and maximal between six 
Table 1. Effect of large single oral doses of diallylmelamine on the heart rate $(H R)$ and mean arterial pressure (MAP) of trained unanesthetized normotensive dogs

\begin{tabular}{|c|c|c|c|c|c|c|c|c|}
\hline \multirow{2}{*}{$\begin{array}{l}\text { Hours } \\
\text { after } \\
\text { Drug }\end{array}$} & \multicolumn{2}{|c|}{$\begin{array}{c}\text { Dog } 1024 \\
50 \mathrm{mg} / \mathrm{kg}\end{array}$} & \multicolumn{2}{|c|}{$\begin{array}{l}\text { Dog } 2100 \\
50 \mathrm{mg} / \mathrm{kg}\end{array}$} & \multicolumn{2}{|c|}{$\begin{array}{l}\text { Dog } 2077 \\
25 \mathrm{mg} / \mathrm{kg}\end{array}$} & \multicolumn{2}{|c|}{$\begin{array}{l}\text { Dog } 2113 \\
25 \mathrm{mg} / \mathrm{kg}\end{array}$} \\
\hline & $\begin{array}{c}\mathrm{HR} \\
\text { beats/min }\end{array}$ & $\underset{\mathrm{mm} \mathrm{Hg}}{\text { MAP }}$ & $\underset{\text { beats/min }}{\mathbf{H R}}$ & $\underset{\mathrm{mm} \mathrm{Hg}}{\text { MAP }}$ & $\begin{array}{c}\text { HR } \\
\text { beats/min }\end{array}$ & $\begin{array}{c}\text { MAP } \\
\mathrm{mm} \mathrm{Hg}\end{array}$ & $\begin{array}{c}\mathrm{HR} \\
\text { beats } / \mathrm{min}\end{array}$ & $\begin{array}{c}\text { MAP } \\
\mathrm{mm} \mathrm{Hg}\end{array}$ \\
\hline Control & 78 & 98 & 126 & 118 & 102 & 110 & 60 & 97 \\
\hline 1 & 204 & 94 & 162 & 125 & 216 & 148 & 78 & 105 \\
\hline 2 & 196 & 90 & 180 & 90 & 276 & 110 & 96 & 106 \\
\hline 4 & 192 & 108 & 228 & 90 & 204 & 76 & 150 & 94 \\
\hline 6 & 192 & 60 & 240 & 84 & 216 & 76 & 180 & 84 \\
\hline 24 & 192 & 81 & 216 & 86 & 204 & 94 & 182 & 93 \\
\hline 48 & - & - & 174 & 102 & 168 & 90 & 168 & 97 \\
\hline 72 & - & - & 168 & 90 & 144 & 117 & - & - \\
\hline 96 & 108 & 140 & 144 & 106 & 144 & 134 & - & - \\
\hline 168 & 72 & 128 & - & - & - & - & - & - \\
\hline
\end{tabular}

Table 2. Hypotensive action of single oral doses of diallylmelamine in unanesthetized hypertensive dogs

\begin{tabular}{|c|c|c|c|c|c|c|c|c|c|c|}
\hline \multirow{2}{*}{$\begin{array}{l}\text { Dog } \\
\text { No. }\end{array}$} & \multirow{2}{*}{$\begin{array}{c}\text { Dose } \\
(\mathrm{mg} / \mathrm{kg})\end{array}$} & \multicolumn{4}{|c|}{$\begin{array}{c}\text { Control Mean } \\
\text { Arterial Pressure }\end{array}$} & \multicolumn{5}{|c|}{$\begin{array}{c}\mathrm{mm} \text { Hg Change } \\
\text { Hours after Dose }\end{array}$} \\
\hline & & Mon & Tues & Wed & Average & 3 & 6 & 24 & 30 & 54 \\
\hline $\begin{array}{l}2072 \\
2105 \\
3109 \\
3569\end{array}$ & 1 & $\begin{array}{l}158 \\
140 \\
130 \\
128\end{array}$ & $\begin{array}{c}160 \\
166 \\
144 \\
128 \\
\text { Av }\end{array}$ & $\begin{array}{l}166 \\
152 \\
138 \\
116 \\
\text { ge }\end{array}$ & $\begin{array}{l}161 \\
153 \\
137 \\
124 \\
144\end{array}$ & $\begin{array}{r}-9 \\
-21 \\
-9 \\
-8 \\
-12\end{array}$ & $\begin{array}{r}-35 \\
-3 \\
-29 \\
-18 \\
-21\end{array}$ & $\begin{array}{l}-23 \\
-1 \\
-21 \\
-14 \\
-15\end{array}$ & $\begin{array}{r}-19 \\
-3 \\
-21 \\
+16 \\
-7\end{array}$ & $\begin{array}{r}-27 \\
+\quad 7 \\
-17 \\
+22 \\
-4\end{array}$ \\
\hline $\begin{array}{l}2072 \\
2105 \\
3109 \\
3569\end{array}$ & 2 & $\begin{array}{l}158 \\
146 \\
152 \\
118\end{array}$ & $\begin{array}{r}158 \\
150 \\
136 \\
120 \\
\text { Av }\end{array}$ & $\begin{array}{l}142 \\
148 \\
144 \\
112 \\
\text { age }\end{array}$ & $\begin{array}{l}153 \\
148 \\
144 \\
117 \\
140\end{array}$ & $\begin{array}{r}-13 \\
+2 \\
-14 \\
-23 \\
-12\end{array}$ & $\begin{array}{l}-23 \\
-2 \\
-44 \\
-27 \\
-24\end{array}$ & $\begin{array}{l}-31 \\
+10 \\
-30 \\
-15 \\
-16\end{array}$ & $\begin{array}{l}-13 \\
-16 \\
-12 \\
-15 \\
-14\end{array}$ & $\begin{array}{r}-25 \\
+\quad 4 \\
-12 \\
-3 \\
-9\end{array}$ \\
\hline $\begin{array}{l}2072 \\
2105 \\
3109 \\
3569\end{array}$ & 5 & $\begin{array}{l}154 \\
165 \\
130 \\
134\end{array}$ & $\begin{array}{r}134 \\
154 \\
138 \\
130 \\
\text { Av }\end{array}$ & $\begin{array}{l}126 \\
150 \\
132 \\
114 \\
\text { age }\end{array}$ & $\begin{array}{l}138 \\
145 \\
133 \\
126 \\
138\end{array}$ & $\begin{array}{r}-8 \\
+\quad 6 \\
-29 \\
-38 \\
-17\end{array}$ & $\begin{array}{l}-10 \\
-44 \\
-49 \\
-44 \\
-37\end{array}$ & $\begin{array}{l}-4 \\
-28 \\
-25 \\
-16 \\
-18\end{array}$ & $\begin{array}{l}-2 \\
-14 \\
-19 \\
+\quad 6 \\
-7\end{array}$ & $\begin{array}{l}+2 \\
-10 \\
-19 \\
+2 \\
-6\end{array}$ \\
\hline $\begin{array}{l}2072 \\
2105 \\
3109 \\
3569\end{array}$ & 10 & $\begin{array}{l}158 \\
138 \\
128 \\
132\end{array}$ & $\begin{array}{r}170 \\
134 \\
126 \\
144 \\
\text { Av }\end{array}$ & $\begin{array}{l}198 \\
138 \\
128 \\
158 \\
\text { age }\end{array}$ & $\begin{array}{l}175 \\
137 \\
127 \\
145 \\
146\end{array}$ & $\begin{array}{l}-5 \\
-19 \\
-37 \\
-39 \\
-25\end{array}$ & $\begin{array}{l}-73 \\
-33 \\
-53 \\
-57 \\
-54\end{array}$ & $\begin{array}{r}-51 \\
+\quad 1 \\
-21 \\
-47 \\
-30\end{array}$ & $\begin{array}{l}-39 \\
+31 \\
-11 \\
-35 \\
-14\end{array}$ & $\begin{array}{r}-35 \\
+\quad 7 \\
-15 \\
-25 \\
-17\end{array}$ \\
\hline
\end{tabular}

and twenty-four hours. Similar latent periods were noted when the compound was injected intravenously.

Neither changes in behavior of these animals nor signs of toxicity were observed. 


\section{Blood pressure in hypertensive dogs}

Dose-response relationships were studied in four renal hypertensive dogs in oral doses ranging from 1 to $10 \mathrm{mg} / \mathrm{kg}$ (Table 2), each dog receiving each dose level, but arranged so that no more than two animals received the same dose in any one week. The latent period noted earlier persisted in the hypertensive animal. Maximum recorded effect was at six hours, although it is likely that the actual peak occurred somewhat later. The $1.0 \mathrm{mg} / \mathrm{kg}$ dose appeared to be near threshold.

\section{Blood pressure in unanesthetized rats following chronic treatment}

Diallylmelamine was administered at a dose of $25 \mathrm{mg} / \mathrm{kg}$ twice daily for 11 or 12 days to both hypertensive and normotensive rats. Control pressures were measured before starting drug and on the two preceding

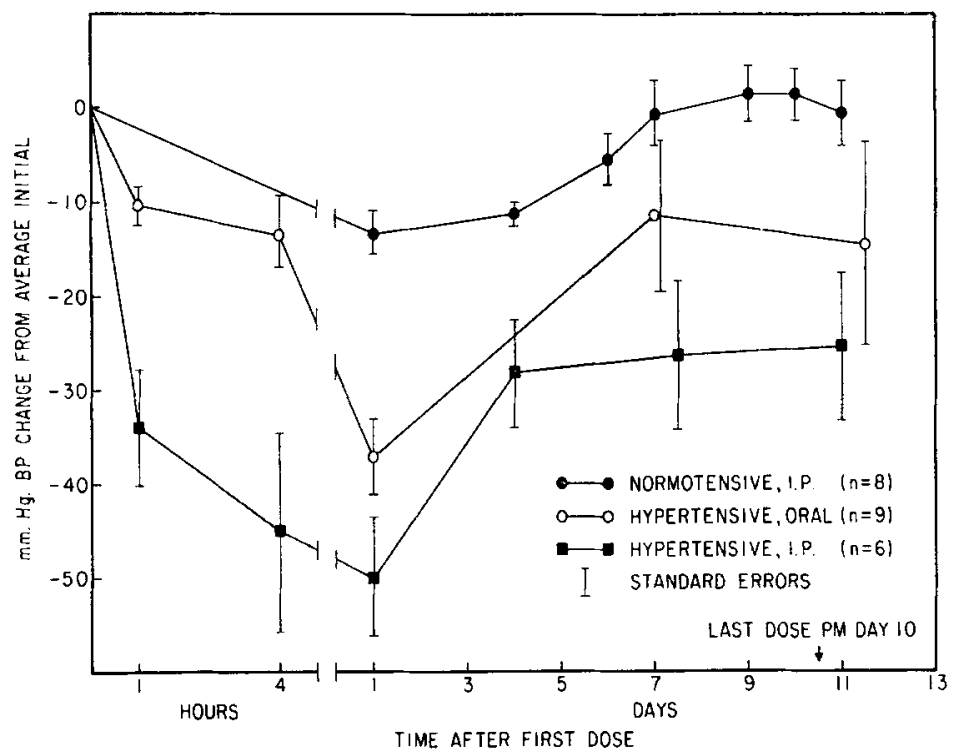

Hig. 1. Hypotensive action of twice daily administration of diallylmclamine $(25 \mathrm{mg} / \mathrm{kg})$ to unancsthetized rats for 11 days. Average initial blood pressure $\pm \mathrm{S}$. E. (each initial the mean of three obscrvations) were: normotensive, $123 \pm 1.6$; hypertensive oral group, $175 \pm 6.2$; and hypertensive $\mathrm{i}$. $\mathrm{p}$. group, $196 \pm 8.6$. In the hypertensive oral group, $6 / 9$ rats were treated 12 instead of 11 days, the final pressures for all averaged and plotted between days 11 and 12. In the hypertensive i. p. group, one rat was observed on day 3 instead of 4 , this value averaged with other day 4 values; and half the rats were observed on day 7 and the others day 8 , the results averaged together and plotter! between these 2 days

days. Results in Fig. 1 are plotted as $\mathrm{mm} \mathrm{Hg}$ change from the average initial pressure. For hypertensive rats, blood pressure was measured 1, 4 and 24 hours after the first dose, and then spotted throughout the rest of the test period, each measurement being made before administration of the first dose of the drug for that day (i.e., approximately sixteen hours 
after dosing). Normotensive rats were treated similarly except that acute observations after 1 and 4 hours were omitted. Maximum decrease in pressure averaged $53 \mathrm{~mm} \mathrm{Hg}$ (range $31-71$ ) and sustained decrease approximately $25 \mathrm{~mm} \mathrm{Hg}$.

Orally, in hypertensive rats, there was no marked pressure fall within four hours, but there was a maximum recorded hypotensive effect by the following morning. This effect averaged $37 \mathrm{~mm} \mathrm{Hg}$ (range 23-57). As the test progressed, pressure came back toward initial values in most of the rats.

In normotensive animals the pressure fall was less marked and was not maintained.

\section{Cardiac output in dogs}

The results of cardiac output determinations in trained unanesthetized dogs appear in Table 3 . There was a marked increase, usually a doubling, of cardiac output after diallylmelamine despite the reduced perfusion pressure. This increase persisted for several days following a single dose of the drug. Thus peripheral resistance, expressed as the quotient of mean arterial pressure and cardiac output, was markedly reduced. The lack of major change in oxygen uptake or in respiratory rate after the drug suggests that the animals were not excited during the drug period.

Since there was a marked tachycardia after diallylmelamine, cardiac output effects were also evaluated during a tachycardia induced by atropine. Data on dog No. 3600 show a similar cardio-acceleration after the atropine without an accompanying cardiac output increase. In this animal, diallylmelamine, administered after atropine, caused a doubling of cardiac output.

To determine whether sympathetic stimulation played a major role in the cardiac output increase, data were obtained in a dog (No. 3827) with thoracic sympathetic supply to the heart surgically extirpated (removal of thoracic sympathetic ganglia down to D-6 bilaterally in two stages, the second stage surgery preceding the test period by three weeks). In this animal, diallylmelamine still doubled cardiac output. Thus, the cardiac output increase after this agent was dependent neither upon the accompanying tachycardia nor the thoracic sympathetic innervation of the heart.

\section{Sympathetic reactivity}

A plot of blood pressure measurements and pressor responses to brief periods of bilateral carotid artery occlusion in dog No. 425 are depicted in Fig. 2. Results in two other animals were qualitatively the same. The hypotensive effect of diallylmelamine was maximal on the first day with partial recovery as the drug was continued. The pressor response to 
44 Walter A. Freyburger, James R. Weeks, and Donald W. Ducharme:

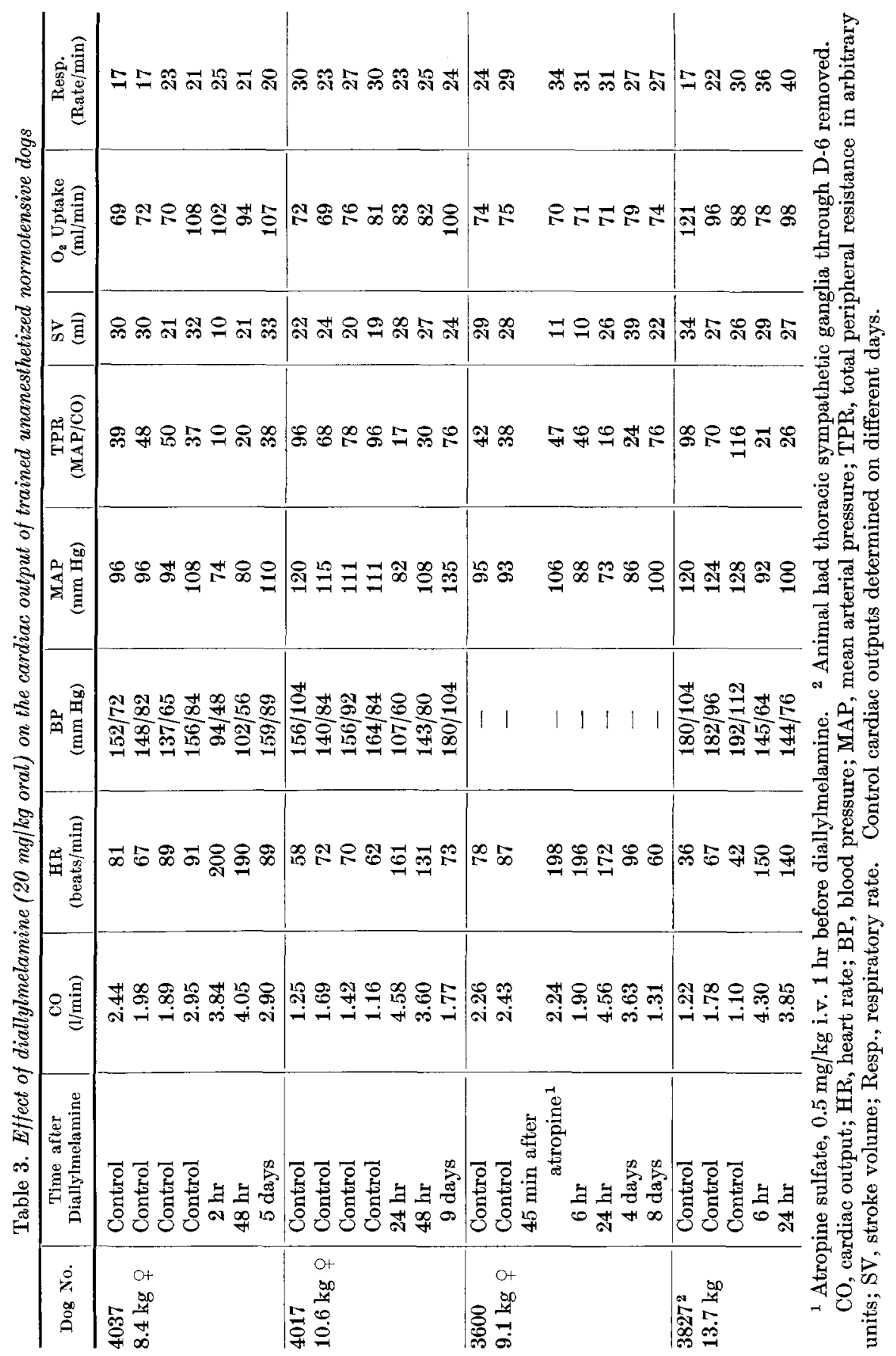


Cardiovascular actions of diallylmelamine

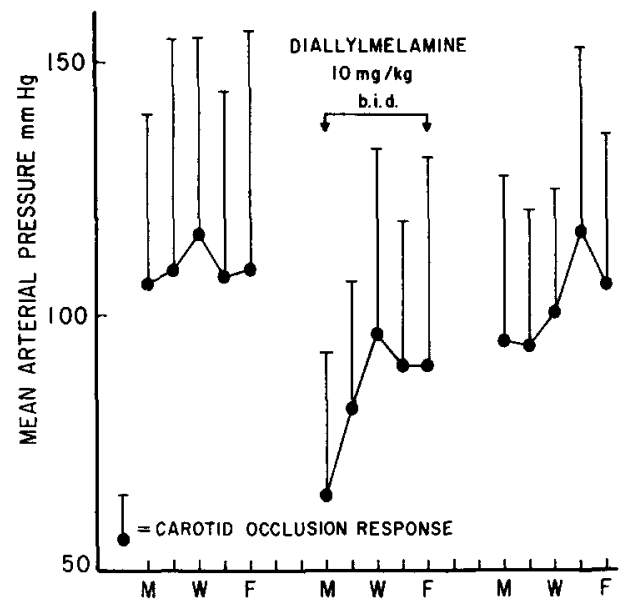

Fig.2. Effect of diallylmelamine on sympathetic reactivity in an unanesthetized dog

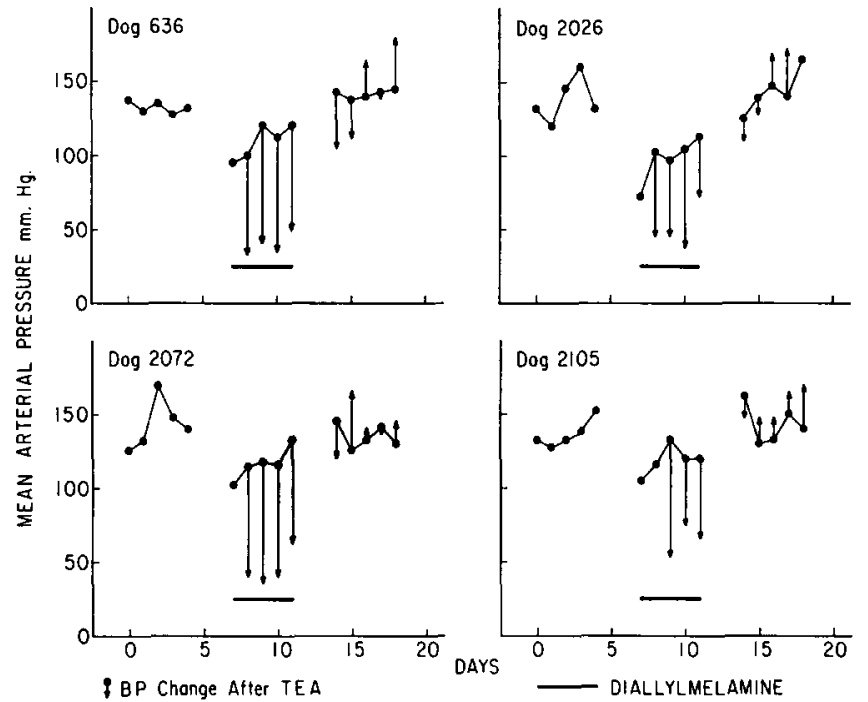

Fig. 3. Influence of diallylmelamine (25 mg/kg oral daily) on the blood pressure response to tetraethylammonium bromide $(5 \mathrm{mg} / \mathrm{kg}$ i.v.) in unanesthetized dogs

carotid occlusion was not blocked by the drug, although it may have been depressed somewhat initially. It is concluded that diallylmelamine does not effect significant impairment of sympathetic reactivity as measured by the pressor response to biliteral carotid occlusion.

\section{Sympathetic activity}

All four dogs tested experienced a marked fall in mean arterial pressure in response to intravenous tetraethylammonium bromide (TEA) 
while treated with diallylmelamine. When treatment was stopped, the depressor response to TEA was lost gradually over a period of two to four days. Responses to TEA were not obtained during the control period because TEA does not normally have hypotensive activity in unanesthetized dogs lying in the supine position (MAXwELL et al. 1956; Freyburaer, unpublished). Fig. 3 is the graph of blood pressure responses to diallylmelamine and to TEA in these dogs. It indicates that this drug does not depress sympathetic vasoconstrictor activity. In fact, activity susceptible to blockade by TEA increased significantly, presumably as part of the homeostatic attempt to compensate for the hypotensive action of diallylmelamine.

Since the compound does not lower arterial pressure by effecting a decrease in cardiac output or by suppressing sympathetic activity it is suggested that it has some direct action on resistance vessels and can therefore be termed a vasodilator substance. The mechanism of this vasodilator effect has not as yet been elucidated.

\section{Discussion}

Arterial pressure is the resultant of delivering a volume of blood (cardiac output) into a reservoir (arterial tree) from which flow is limited by the state of tone in the smaller vessels (peripheral resistance). The foregoing data show diallylmelamine increases cardiac output. If pressure falls significantly despite an increased output of the heart, peripheral resistance must be decreased markedly. Since sympathetic vasoconstrictor activity appears not to be depressed by this drug, certainly this agent must act to decrease peripheral resistance by some mechanism other than blockade of sympathetic vasoconstrictor tone. Although such factors as activation of vasodilator nerves or decreasing blood viscosity have not been ruled out, it appears likely that this compound acts directly upon vascular smooth muscle.

The relatively long latent period and relatively poor dose response relationship obtained in the dog suggest that diallylmelamine might not be a hypotensive agent per se but that it might be converted in the body to an active metabolite. This possibility is being investigated.

\section{Summary}

Diallylmelamine is an effective hypotensive agent in hypertensive dogs and rats, having a duration of action exceeding twenty-four hours from a single oral dose. It has limited efficacy in normotensive rats. Hypotensive activity of gradual onset is preceded by a latent period of up to two hours and becomes maximal six hours or more after dosing. This agent does not depress cardiac output or sympathetic vasoconstrictor activity. It is suggested that its hypotensive activity results from a direct effect upon vascular smooth musele. 


\section{References}

Freyburger, W. A., J. R. Weeks, and E. Smits: Hypotensive action of N,Ndiallylmelamine (U-7720) in trained unanesthetized dogs. Pharmacologist 4, 165 (1962).

Goldblatt, H., J. Lynch, R. F. Hanzal, and W. W. Summerville: Studies on experimental hypertension: I. The production of persistent elevation of systolic blood pressure by means of renal ischemia. J. exp. Med. 59, 347 (1934).

Grollman, A.: A simplified procedure for inducing chronic renal hypertension in the mammal. Proc. Soc. exp. Biol. (N. Y.) 57, 102 (1944).

Heatley, N. G., and J. R. Weeks: Fashioning polyethylene tubing for use in physiological experiments. J. appl. Physiol. 19, 542 (1964).

LeERSum, E. C. var: Eine Methode zur Erleichterung der Blutdruckmessung bei Tieren. Pflügers Arch. ges. Physiol. 142, 377 (1911).

Maxwell, R. A., A. J. Plummer, and M. W. Osborne : Studies with the ganglionic blocking agent, chlorisondamine chloride in unanesthetized and anesthetized dogs. Circulat. Res. 4, 276 (1956).

WEEks, J. R., and J. A. Jones: Routine direct measurement of arterial pressure in unanesthetized rats. Proc. Soc. exp. Biol. (N. Y.) 104, 646 (1960).

Watter A. Freyburger, Ph. D.,

Dept. of Pharmacology, The Upjohn Company, Kalamazoo, Michigan 49001, U.S.A. 